\title{
Can the Additional Dose Requirement be Determined before the Seventh Day to Successfully Treat Tubal Ectopic Pregnancy with a Single-dose Methotrexate Protocol?
}

\author{
Burak Akselim, Süleyman Serkan Karaşin and Yeliz Acar Sabır \\ Department of Obstetrics and Gynecology, Bursa Yüksek İhtisas Training and Research Hospital, Bursa, Turkey
}

\begin{abstract}
Objective: To investigate the relationship of beta-hCG changes between the first, fourth and seventh days as a predictor of the additional dose requirement in single-dose methotrexate protocol in tubal ectopic pregnancy.

Study Design: Observational study.

Place and Duration of Study: Department of Obstetrics and Gynecology, Bursa Yüksek ihtisas Training and Research Hospital, between January 2017 and June 2020.

Methodology: Data of 123 patients with tubal ectopic pregnancy, treated with a single-dose methotrexate protocol, were retrospectively analysed. Patients who received methotrexate on the first day and achieved treatment success constituted one group. Patients who received additional doses on the seventh day and achieved treatment success, constituted the other group. Treatment success was defined as normalisation of beta-hCG levels without surgical intervention.

Results: The percentage of beta-hCG change between day-one and day-four was a significant independent variable for the additional dose treatment requirement (OR:1.07, Cl:1.01-1.13, $\mathrm{p}=0.022$ ). The cut-off value of the beta-hCG change percentage between the first and fourth day, was calculated as $4 \%$ (sensitivity $72.9 \%$, specificity $78.9 \%$, positive predictive value [PPV] $88.6 \%$, negative predictive value [NPV] $56.6 \%$ ).

Conclusion: In the single-dose methotrexate protocol applied in the medical treatment of tubal ectopic pregnancy, the change in beta-hCG value between the first and fourth days may predict the need for additional doses. Administration of an additional dose of methotrexate on the fourth day may be considered, if there is less than a $4 \%$ decrease or any increase in beta-hCG value between the first and fourth days.
\end{abstract}

Key Words: Ectopic pregnancy, Methotrexate, Beta human chorionic gonadotropin, Tubal pregnancy, Single-dose protocol.

How to cite this article: Akselim B, Karaşin SS, Sabır YA. Can the Additional Dose Requirement be Determined before the Seventh Day to Successfully Treat Tubal Ectopic Pregnancy with a Single-dose Methotrexate Protocol?. J Coll Physicians Surg Pak 2021; 31(09):1046-1050.

\section{INTRODUCTION}

Ectopic pregnancy describes the gestational sac located outside the uterine cavity and mostly develops in the fallopian tube. The diagnosis of ectopic pregnancy is based on a combination of beta human chorionic gonadotropin (hCG) levels, ultrasound findings, and clinical symptoms. Ectopic pregnancy may be asymptomatic, and it may also present with first-trimester vaginal bleeding orabdominal pain. ${ }^{1}$ Rupture of an ectopic pregnancy can cause life-threatening bleeding. ${ }^{2}$

Correspondence to: Dr. Burak Akselim, Department of Obstetrics and Gynecology, Bursa Yüksek İhtisas Training and Research Hospital, Bursa, Turkey

E-mail: burakakselim@hotmail.com

Received: February 24, 2021; Revised: July 18, 2021;

Accepted: August 20, 2021

DOI: https://doi.org/10.29271/jcpsp.2021.09.1046
The use of methotrexate may be considered an alternative to surgical treatment, especially in treating patients with hemodynamically stable, non-ruptured ectopic pregnancy and early diagnosis. ${ }^{3}$ There are three protocols for methotrexate administration in treating ectopic pregnancy, namely single-dose, double-dose, and fixed multiple-dose. ${ }^{4}$ The single-dose regimen is the simplest and is as effective as the fixed multi-dose regimen, eliminating the need for folinic acid to minimise side effects. ${ }^{5}$ This protocol has the advantages of not requiring a recovery regimen, lower incidence of side effects, and better compliance. ${ }^{6}$ Follow-up of patients treated with a single-dose protocol includes assessing beta-hCG levels on days 1,4 , and 7 . A $15 \%$ decrease in beta-hCG level is expected from day 4 to day 7. If there is not enough decrease in the control beta-hCG value on the 7th day, the same dose is repeated, and the beta-hCG level is rechecked on the 14 th day. ${ }^{4}$

However, this protocol's disadvantage is that seven days must be 
waitedfor, beforethetreatment'seffectiveness isevaluated. Determining the need for additional doses and the success of the treatment earlier in the treatment protocol may reduce complications such as rupture during the waiting and reduce the patient's anxiety and increase patientcompliance.

The aim of this study was to investigate the relationship of betahCG changes between the first, fourth and seventh days as a predictor of the additional dose requirement in single-dose methotrexate protocol in tubal ectopic pregnancy successful treatment.

\section{METHODOLOGY}

This study was conducted retrospectively between January 2017 and June 2020 by including 123 patients admitted to the Bursa Yuksek Ihtisas Training and Research Hospital, diagnosed with tubal ectopic pregnancy, and treated with single-dose MTX protocol successfully. It was approved by the Ethics Committee of the Bursa Yuksek Ihtisas Training and Research Hospital.

Ectopic pregnancy was diagnosed by standard set criteria based on clinical, ultrasonographic, and serial hCG values. All eligible women, who agreed to receive a single dose methotrexate protocol for ectopic pregnancy, were included. Inclusion criteria were hemodynamically stable, non-ruptured tubal ectopic pregnancies, and no contraindications for methotrexate therapy. The exclusion criteria werewomen with acute ruptured ectopic pregnancies, non-tubal ectopic pregnancies, hCG levels were obtained outside the protocol, incomplete follow-up or medical records were incomplete, and women who were operated upon after methotrexate administration. Relevant clinical, ultrasonographical, and laboratory data were obtained from electronic patient records. Clinical outcome was analysed, based on whether hCG levels were entirely resolved or additional methotrexate doses were needed, or surgery was performed. Patient enrollment is summarized in Figure 1.

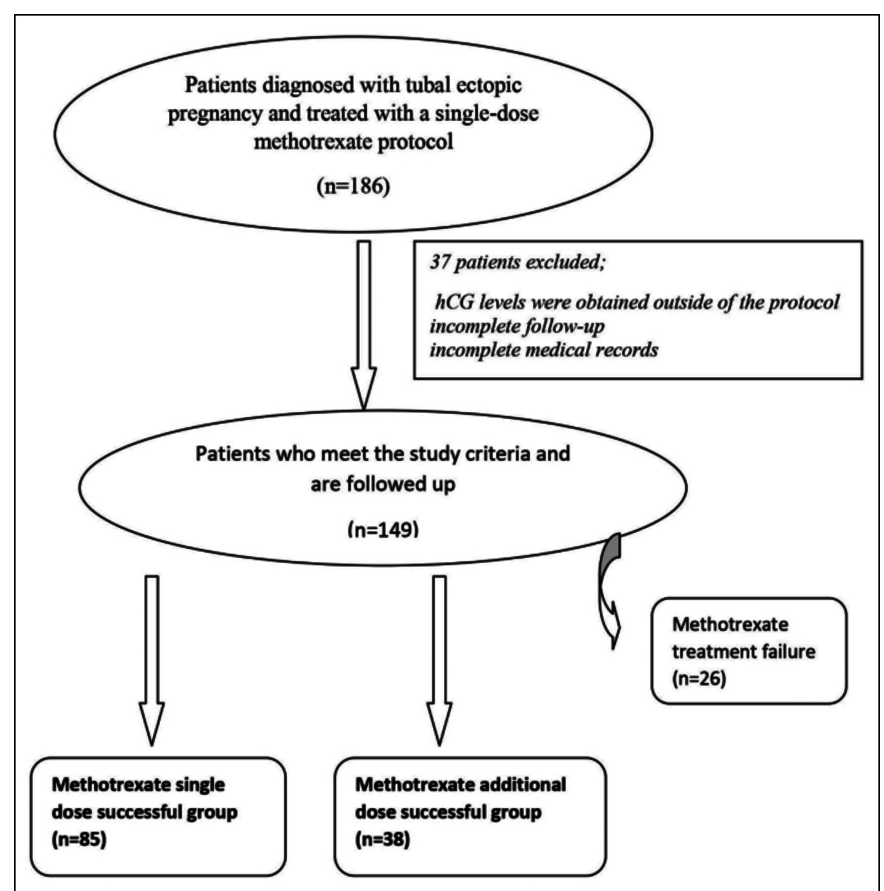

Figure 1: Patient enrollment summary.
According to the single-dose protocol, beta-hCG levels were measured simultaneously while applying 50mg/m2 methotrexate to each suitable patient (Day 1). ${ }^{4,7}$ Beta-hCG change percentages were calculated on the fourth and seventh days after methotrexate application (e.g., ([beta-hCG day 4 beta-hCG day 1] / beta-hCG day 1) x 100). Accordingly, a single dose was considered successful in patients with a decrease of more than $15 \%$ in hCG from the fourth day to the seventh day and invited them to clinical follow-up. Beta-hCG values regularly decreased during weekly follow-up in this group of patients. An additional dose was administered to patients whose beta-hCG decrease was less than 15 percent on the seventh day. After the additional dose, the patients whose betahCG levels did not decrease as desired were either re-administered methotrexate or surgical treatment. These patients were also excluded from the study. The patients were divided into two groups; patients whose treatment was successful after the first dose of methotrexate (methotrexate single dose successful group), and patients who were administered additional dose methotrexate on the seventh day and the treatment was successful (methotrexate additional dose successful group). Treatment success was defined as normalisation of beta-hCG levels with single-dose methotrexate protocol without surgical intervention.

For proper statistical analyses, a Windows-based SPSS 24.0 statistical analysis programme was used (SPSS Inc., USA), to determine whether they were normally distributed or not, variables were examined via, visual (histograms, probability plots) and analytical methods (Shapiro-Wilk's test). Variables were descriptively specified as mean \pm standard deviation $(X \pm S D)$, median (IQR: 25th percentile-75th percentile), frequency $(n)$, and percentage (\%). Student t-test and Mann-Whitney U-test were used to compare normally distributed and undistributed variables in two group analyses. Logistic regression analysis was performed with the data found to be significant in the previous test to determine independent factors between the successful single-dose methotrexate and the additional second dose methotrexate treated groups. ROC analysis was used to determine the beta-hCG change cut-off values between the fourth and first days in terms of the need for second dose methotrexate. The level of statistical significance was set at $p$ $<0.05$.

\section{RESULTS}

There was no significant difference between age, gravidity, parity, and body mass index (p: 0.920, 0.848, 0.433 and, 0.874), respectively. As shown in Table I, the first, fourth, and seventh days of beta-hCG values were statistically different between the groups ( $p<0.05$ ). While the median value of beta-hCG was $887.0 \mathrm{mIU} / \mathrm{mL}$ on the first day in the single-dose methotrexate successful group, the beta-hCG value was $2534.0 \mathrm{mIU} / \mathrm{mL}$ on the first day in the group that required the additional dose. This difference was statistically significant $(p=0.002)$ (Table I).

The beta-hCG change percentages between the two groups were also analysed. Percentage changes from the first day to 
the fourth, from the fourth day to the seventh, and from the first day to the seventh day were statistically different between groups. $(p<0.001$, Tablel).

However, if the rate of decrease in beta-hCG values decreases, the possibility of giving a second dose of methotrexate to patients may increase (Tablel).

Table I: Comparison of single-dose successful group and additional dose successful group in terms of beta-hCG values and change percentages.

\begin{tabular}{|c|c|c|c|}
\hline & \multirow{2}{*}{\begin{tabular}{|c}
$\begin{array}{c}\text { Methotrexate single- } \\
\text { dose successful group } \\
(\mathrm{n}=85)\end{array}$ \\
mean \pm SD/media \\
$(\mathrm{IQR})$
\end{tabular}} & \multirow{2}{*}{$\begin{array}{c}\begin{array}{c}\text { Methotrexate } \\
\text { additional dose } \\
\text { successful group } \\
(n=38)\end{array} \\
\text { mean } \pm \text { SD/media } \\
(\text { IQR) }\end{array}$} & \multirow[t]{2}{*}{$\mathbf{p}$} \\
\hline & & & \\
\hline Age (years) & $32.1 \pm 6.7$ & $31.9 \pm 5.7$ & 0.920 \\
\hline Gravidity & $3(2-3.5)$ & $3(2-4)$ & 0.848 \\
\hline Parity & $1(0-2)$ & $1(0-2)$ & 0.433 \\
\hline $\begin{array}{l}\text { Body mass } \\
\text { index }\left(\mathrm{kg} / \mathrm{m}^{2}\right)\end{array}$ & $24.3(22.5-26.6)$ & $24.0(22.4-27.3)$ & 0.874 \\
\hline $\begin{array}{l}\text { First day of } \\
\text { beta-hCG }\end{array}$ & $887.0(473.5-2370.0)$ & $\begin{array}{c}2534.0 \\
(689.2-4736.5) \\
\end{array}$ & 0.002 \\
\hline $\begin{array}{l}\text { Fourth day of } \\
\text { beta-hCG }\end{array}$ & $694.0(299.5-1395.5)$ & $\begin{array}{c}3011.0 \\
(843.0-5005.7)\end{array}$ & $<0.001$ \\
\hline $\begin{array}{l}\text { Seventh day } \\
\text { of beta-hCG }\end{array}$ & $495.0(159.5-809.0)$ & $\begin{array}{c}2421.0 \\
(599.7-3890.0)\end{array}$ & $<0.001$ \\
\hline $\begin{array}{l}\text { Percentage } \\
\text { change from } \\
\text { first day to } \\
\text { fourth (\%, } \\
\text { beta-hCG) }\end{array}$ & $-26.3(-46-3.6)$ & $18.7(-2.2-50.3)$ & $<0.001$ \\
\hline $\begin{array}{l}\text { Percentage } \\
\text { change from } \\
\text { fourth day to } \\
\text { seventh (\%, } \\
\text { beta-hCG) }\end{array}$ & $-39.2 \pm 25.5$ & $-19.6 \pm 30.2$ & $<0.001$ \\
\hline $\begin{array}{l}\text { Percentage } \\
\text { change from } \\
\text { first day to } \\
\text { seventh (\%, } \\
\text { beta-hCG) }\end{array}$ & $-53.5(-75.6-[-27.6])$ & $-10(-36.8-16.7)$ & $<0.001$ \\
\hline $\begin{array}{l}\text { SD: Standart d } \\
\text { groups, }{ }^{\beta} \text { Mann } \\
\text { Minimum, Max }\end{array}$ & $\begin{array}{l}\text { 1, Student t-test use } \\
\text { ey U-test used in con } \\
\text { hum. }\end{array}$ & $\begin{array}{l}\text { omparisons betw } \\
\text { on between grou }\end{array}$ & en \\
\hline
\end{tabular}

A logistic regression analysis was performed to identify independent variables for predicting a methotrexate second dose treatment requirement. Percentage of beta-hCG changes between day one and day four; and the percentage of beta-hCG changes between day four and day seven were found significant independent variables for the additional dose treatment requirement. Each 1 percent increase in beta-hCG from day 1 to day 4 increases the additional dose requirement by 1.04 times (Tablell).

The serum beta-hCG change percentage between day one and day 4 in predicting additional dose methotrexate requirement was analysed using ROC (receiver operating characteristics) curve analysis. Looking at the ROC curve and the table of the area under the curve (AUC), it was seen that beta-hCG changes from the first day to the fourth day has the diagnostic mean in the prediction of the second dose of methotrexate therapy. On the other hand, a change of at least minus 4 percent in beta-hCG value from the first day to the fourth day was found an essential valuable variable (AUC [95\% Cl]: 0.795 [0.714-0.876], $\mathrm{p}<0.001$ ). This cut-off would provide sensitivity $72.9 \%$ and specificity $78.9 \%$. The positive predictive value was $88.6 \%$, and the negative predictive value was $56.6 \%$. These values are significant for the exclusion of the additional dose requirement.

Table II: Logistic regression analyses of parameters between the single dose successful group and additional dose successful group.

\begin{tabular}{|l|c|c|c|}
\hline \multirow{2}{*}{} & \multicolumn{3}{|c|}{$\begin{array}{c}\text { Binary logistic regression analyses } \\
\text { results }\end{array}$} \\
\cline { 2 - 4 } & OR & Cl & p \\
\hline First day of beta-hCG ${ }^{\beta}$ & 1.0 & $1-1.0$ & 0.359 \\
\hline Fourth day of beta-hCG ${ }^{\beta}$ & 1.0 & $1.0-1.0$ & 0.091 \\
\hline Seventh day of beta-hCG ${ }^{\beta}$ & 1.0 & $1-1.0$ & 0.699 \\
\hline $\begin{array}{l}\text { Percentage change in } \\
\text { beta-hCG from first day to } \\
\text { fourth }\end{array}$ & 1.04 & $1.0-1.08$ & $0.033^{*}$ \\
\hline $\begin{array}{l}\text { Percentage change in } \\
\text { beta-hCG from fourth day } \\
\text { to seventh }\end{array}$ & 1.07 & $1.01-1.13$ & $0.022^{*}$ \\
\hline $\begin{array}{l}\text { Percentage change in } \\
\text { beta-hCG from first day to } \\
\text { seventh }\end{array}$ & 0.97 & $0.93-1.01$ & 0.179 \\
\hline $\begin{array}{l}\text { Cl (95\%) coinfidence interval; OR: Odds ratio; Wald: Test statistics value. } \\
\text { Single-dose methotrexate successful group was taken as the reference } \\
\text { category. Nagelkerke } R^{2}=0.500 \text { and the models fit well with the data. }\end{array}$ \\
\hline
\end{tabular}

\section{DISCUSSION}

After using methotrexate in suitable patients in the treatment of ectopic pregnancy was offered as an alternative to laparoscopic treatment, protocols were started to be defined to increase treatment success and patient compliance and minimise drug side effects.

Single-dose methotrexate protocol has been used in the medical treatment of ectopic pregnancy for about 30 years. ${ }^{7}$ It is preferred more widely because of its low side effect profile and the similarity of treatment success efficiency with other drug use protocols. ${ }^{8,9}$ Since evaluating the treatment's success can be done on the seventh day at the earliest after the drug is administered, the possibility of treatment failure during this period may cause an increase in patient anxiety and decrease patient compliance. For this reason, studies have been conducted to develop the protocol and determine the treatment's success before the seventh day, examining the values of beta-hCG and its changes between days.

Although the relationship between initial beta-hCG value and the success of single-dose methotrexate protocol and ectopic pregnancy treatment is well defined in the literature, there are different results for the cut-off value. This value was determined as $2000 \mathrm{mlU} / \mathrm{mL}$ by Sagiv et al., $1790 \mathrm{mIU} / \mathrm{mL}$ by Nowak-Markowitz et al. ${ }^{11}$, and $1300 \mathrm{mIU} / \mathrm{mL}$ by Rabischong et al. ${ }^{10-12} \mathrm{~A}$ review stated that if the initial beta-hCG value is above 5000 $\mathrm{mIU} / \mathrm{mL}$ in the single-dose methotrexate protocol, the treatment's success decreases. ${ }^{13}$ The two-dose protocol was superior to the single-dose protocol in cases where the beta-hCG 
value is $>3000 \mathrm{mIU} / \mathrm{mL} .{ }^{14}$ Cohen et al. stated that in the single-dose protocol, the first-day beta-hCG value is a predictor for additional dose and treatment success, and if it is more than $2234 \mathrm{mlU} / \mathrm{mL}$, there is a need for additional doses. ${ }^{15}$

The results are controversial in determining the success of treatment for the beta-hCG value measured on the fourth day. Girija et al., 4th-day beta-hCG value was found to be high in the unsuccessful treatment group. ${ }^{16}$ On the contrary, publications are stating that it cannot predict treatmentsuccess alone and that it does not even need to be considered in a single dose protocol. ${ }^{17,18}$ In the present study, on the first day and the fourth day, beta-hCG values were high in the group that required additional doses, but these differences were not useful in predicting the need for additional doses.

The beta-hCG change between the first and the fourth day is the most emphasised issue in determining treatment success and the need for additional doses in the single-dose methotrexate protocol. Significant differences are detected. Goh et al. stated that if there is less than a $5 \%$ increase or any decrease in betahCG value between the first and fourth days, it can predict the treatment's success. ${ }^{19}$ Agostini et al. stated that if there is a decrease of more than $20 \%$, the treatment's success can be predicted, and the risk of surgical treatment and additional dose requirement decreases..$^{20}$ In a study where the change in betahCG value between zero and fourth days was examined, a decrease of less than $18 \%$ was determined as an early determinant of treatment failure. ${ }^{21}$ Moreover, in the same study, if an increase of more than $36 \%$ is detected, it is recommended to give the additional dose on the fourth day. ${ }^{21}$ In these three studies, the application of methotrexate on the seventh day was accepted as a treatment failure. Most studies in the literature have been designed in this way, and treatment success is generally emphasised. This situation is inconsistent with the single-dose protocol defined by Stovall, and the different description of treatment failure in studies creates confusion in terms of results. This study compared the two groups with successful results by administering methotrexate to determine the additional dose requirement on the seventh day in the single-dose methotrexate protocol. In the single-dose methotrexate protocol, the authors found that the need for additional doses applied on the seventh day could be determined from the change in beta-hCG value between the first and fourth days, and the cut-off value for this change was $4 \%$. A decrease of less than $4 \%$ had a relatively high positive predictive value of $88.6 \%$ in determining the need for additional doses of methotrexate. In the study conducted by Yıldırım et al., which was designed similarly to this study, this cutoff value was determined as a $22 \%$ decrease. $^{22}$

One of the strengths of the present study is that the comparison was made in two groups with successful methotrexate treatment to predict the need for additional doses in a single dose protocol. Besides, according to the single-dose protocol, administration of an additional dose on the seventh day was not considered a treatment failure. The limitations of the study are its retrospective nature and the small number of patients.

\section{CONCLUSION}

In the single-dose methotrexate protocol applied in the medical treatment of tubal ectopic pregnancy, an additional dose of methotrexate may be considered on the fourth day, if there is a decrease of less than $4 \%$ or any increase in beta-hCG value between the first and fourth days.

\section{ETHICALAPPROVAL:}

The study was approved by the Ethics Committee of the Bursa Yuksek Ihtisas Training and Research Hospital.

\section{PATIENTS' CONSENT:}

Because this study was retrospective, the patients' consents were waived.

\section{CONFLICT OF INTEREST:}

The authors declared no conflict of interest.

\section{AUTHORS' CONTRIBUTION:}

BA: Project development, data collection and/or processing, analysis and/or Interpretation, literature search, manusript writing, critical reviews.

SSK: Project development, analysis, literature search, manusript writing, critical reviews.

YAS: Data collection and/or processing, literature search, critical reviews.

\section{REFERENCES}

1. Alkatout I, Honemeyer U, Strauss A, Tinelli A, Malvasi A, Jonat $W$, et al. Clinical diagnosis and treatment of ectopic pregnancy. Obstet Gynecol Surv 2013; 68(8):571-81. doi: 10.1097/OGX.0b013e31829cdbeb.

2. Bouyer J, Coste J, Fernandez H, Pouly JL, Job-Spira N. Sites of ectopic pregnancy: A 10 year population-based study of 1800 cases. Hum Reprod 2002; 17(12):3224-3230. doi: 10.1093/humrep/17.12.3224.

3. Medicine PCotASfR. Medical treatment of ectopic pregnancy: A committee opinion. Fertil Steril 2013; 100: 638-644.

4. ACOG Practice Bulletin No. 193: Tubal Ectopic Pregnancy. Obstet Gynecol 2018; 131:e91-e103.

5. Yang C, Cai J, Geng Y, Gao Y. Multiple-dose and doubledose versus single-dose administration of methotrexate for the treatment of ectopic pregnancy: A systematic review and meta-analysis. Reprod Biomed Online 2017; 34(4):383-91. doi: 10.1016/j.rbmo.2017.01.004.

6. Alleyassin A, Khademi A, Aghahosseini M, Safdarian L, Badenoosh B, Hamed EA. Comparison of success rates in the medical management of ectopic pregnancy with singledose and multiple-dose administration of methotrexate: $A$ prospective, randomized clinical trial. Fertil Steril 2006; 85(6):1661-6. doi: 10.1016/j.fertnstert.2005.11.055.

7. Stovall TG, Ling FW. Single-dose methotrexate: An expanded clinical trial. Am J Obstet Gynecol 1993; 168(6 Pt 1):1759-65.

8. Barnhart KT, Gosman G, Ashby R, Sammel M. The medical management of ectopic pregnancy: A meta-analysis comparing "single dose" and "multidose" regimens. Obstet 
Gynecol 2003; 101(4):778-784. doi: 10.1016/s00297844(02)03158-7.

9. Hajenius PJ, Mol F, Mol BW, Bossuyt PM, Ankum WM, van der Veen F. Interventions for tubal ectopic pregnancy. Cochrane Database Syst Rev 2000; 2:Cd000324. doi: 10.1002/14651858.CD000324.

10. Sagiv R, Debby A, Feit H, Cohen-Sacher B, Keidar R, Golan A. The optimal cutoff serum level of human chorionic gonadotropin for efficacy of methotrexate treatment in women with extrauterine pregnancy. Intern J Gynecol Obstet 2012; 116(2):101-4. doi: 10.1016/j.ijgo.2011.09.023.

11. Nowak-Markwitz E, Michalak M, Olejnik M, Spaczynski M. Cutoff value of human chorionic gonadotropin in relation to the number of methotrexate cycles in the successful treatment of ectopic pregnancy. Fertil Steril 2009; 92(4):1203-7. doi: 10.1016/j.fertnstert.2008.07.1775.

12. Rabischong $B$, Tran $X$, Abi Sleiman A, Larraín D, Jaffeux $P$, Aublet-Cuvelier $B$, et al. Predictive factors of failure in management of ectopic pregnancy with single-dose methotrexate: A general population-based analysis from the Auvergne Register, France. Fertil Steril 2011; 95(1):401-4. e401. doi: 10.1016/j.fertnstert.2010.08.025.

13. Menon S, Colins J, Barnhart KT. Establishing a human chorionic gonadotropin cutoff to guide methotrexate treatment of ectopic pregnancy: A systematic review. Fertil Steril 2007; 87(3):481-4. doi: 10.1016/ j.fertnstert. 2006.10.007.

14. Alur-Gupta S, Cooney LG, Senapati S, Sammel MD, Barnhart KT. Two-dose versus single-dose methotrexate for treatment of ectopic pregnancy: A meta-analysis. Am J Obstet Gynecol 2019; 221(2):95-108.e102. doi: 10.1016/j.ajog.2019.01.002.

15. Cohen A, Bibi G, Almog B, Tsafrir Z, Levin I. Second-dose methotrexate in ectopic pregnancies: The role of beta human chorionic gonadotropin. Fertil Steril 2014; 102(6):
1646-9. doi: 10.1016/j.fertnstert.2014.08.019.

16. Girija S, Manjunath A, Salahudin A, Jeyaseelan L, Gowri V, Abu-Heija A, et al. Role of day 4 HCG as an early predictor of success after methotrexate therapy for ectopic pregnancies. Eur J Obstet Gynecol Reprod Biol 2017; 215:230-3. doi: 10.1016/j.ejogrb.2017.06.020.

17. Atkinson M, Gupta S, Mcgee T. $\beta$ hCG monitoring after single-dose methotrexate treatment of tubal ectopic pregnancy: Is the Day $4 \beta$ hCG necessary? A retrospective cohort study. Aust N Z J Obstet Gynaecol 2014; 54(5): 475-9. doi: 10.1111/ajo.12257.

18. Leonardi M, Allison E, Lu C, Nadim B, Condous G. Prognostic accuracy of a novel methotrexate protocol for the resolution of tubal ectopic pregnancies. Eur J Obstet Gynecol Reprod Biol 2020; 247: 186-190. doi: 10.1016/ j.ejogrb.2020.02.029.

19. Goh A, Karine P, Kirby A, Williams C, Kapurubandara S. Day 1 to day 4 serum hCG change in predicting single-dose methotrexate treatment failure for tubal ectopic pregnancies. Eur J Obstet Gynecol Reprod Biol 2020; 255: 105-10. doi: 10.1016/j.ejogrb.2020.10.036.

20. Agostini A, Blanc K, Ronda I, Romain F, Capelle M, Blanc B. Prognostic value of human chorionic gonadotropin changes after methotrexate injection for ectopic pregnancy. Fertil Steril 2007; 88(2):504-6. doi: 10.1016/j.fertnstert. 2006.11.138.

21. Shatkin Hamish N, Wolf M, Tendler R, Sharon A, Bornstein J, Odeh M. Early prediction of methotrexate treatment outcome in tubal ectopic pregnancy based on days 0 and 4 human chorionic gonadotropin levels. J Obstet Gynaecol Res 2020; 46(7):1104-9. doi: 10.1111/jog.14259.

22. Yıldırım A, Cırık DA, Altay M, Gelisen O. Early prediction for the requirement of second or third dose methotrexate in women with ectopic pregnancy, treated with single-dose regimen. Arch Gynecol Obstet 2015; 291(6):1327-32. doi: 10.1007/s00404-014-3593-x. 